\title{
Üniversite Öğrencilerinin Görüşlerine Göre Çağdaş Dünya Tarihi Konularının Tarihsel Önemi
}

\begin{abstract}
Özgür AKTAŞ*
Özet

Bu çalışmanın amacı üniversite öğrencilerinin görüşlerine göre çağdaş dünya tarihi konularının tarihsel önemini önemi ortaya koymaktır. Çalışma nitel bir araştırmadır. Araştırma yöntemi olarak ise durum çalışması deseni kullanılmıştır. Araştırmada Ortaöğretim Çağdaş Türk ve Dünya Tarihi ders kitabı incelenmiş tarihsel olaylar dokuz kategoride toplanmıştır. Öğrencilere bu kategorilerden hangisinin en önemli olduğu şeklinde bir açlk uçlu soru sorulmuştur. Ö̆ğrencilerin verdikleri cevaplar frekans ve yüzde olarak değerlendirilmiştir. Öğrencilerin cevaplarının daha iyi anlaşılabilmesi için öğrencilerin verdikleri cevaplardan örnekler sunulmuştur. Çalışmanın sonuçlarına bakıldığında en fazla öğrenci (\% 46) tarihsel öneme sahip olarak savaşlar kategorisini tercih etmiştir. Öğrenciler önem bakımından ikinci sıradaysa küresel sorunlar konusunu tercih etmiştir. 1929 Dünya ekonomik krizi ve diğer krizler ise en az oranda tercih edilmiştir.
\end{abstract}

Anahtar kelimeler: Tarih eğitimi, tarihsel önem, öğrenci, çağdaş dünya tarihi,

\section{The Historical Importance of the Topics of Modern World History Depending on the Views of University Students}

\begin{abstract}
The purpose of this study to investigate the importance of the topics of modern world history depending on the views of university students. The method of this research is a qualitative survey. The design of the research is a case study. Case studies could be carried out through both quantitative and qualitative approach. The course book of Modern Turkish and World History was examined and the units were determined. The issues given in the units were classified under some certain headings thematically Depending on the findings of the research, it was found that $46.4 \%$ of the students attending to the department of history regarded that wars are the most important events. It was found that second important event $11.6 \%$ thought it was global problems, 1929 World Economic Crisis and other crisis were selected at least important events.
\end{abstract}

Key Words: History education, historical importance, student, modern world history.

*Yrd. Doç. Dr., Kafkas Üniversitesi, ozgurkafkas@gmail.com 


\section{GİRIŞ}

Türkiye'de orta öğretim kurumlarında Çağdaş Türk ve Dünya Tarihi dersinin müfredata konulmasıyla beraber Atatürk döneminden sonra ortaöğretimde ilk defa dünya tarihi konularının öğretimi amacı güdülmüştür. Türkiye Cumhuriyeti İnkılap Tarihi ve Atatürkçülük ders kitaplarında Atatürk'ün ölüm tarihine kadar anlatılan tarihsel olaylar bu ders kitabiyla 2008 yılına kadar anlatılmıştır. Çağdaş Türk ve Dünya Tarihi ders kitabı beş üniteden oluşmaktadır. Ünitelerin isimleri ve oranları şöyledir: XX. Yüzyılın Başlarında Dünya ( \% 19), II. Dünya Savaşı (\% 14), Soğuk Savaş Dönemi (\% 20), Yumuşama Dönemi ve Sonrası (\% 22), Küreselleşen Dünya ( \% 25). Çağdaş Türk ve Dünya tarihi ders kitabında iki dünya savaşı, Arap- İsrail savaşları, Afrika ve Asya'da meydana gelen iç savaşlar anlatılmıştır. Bu kitapta yer alan başka önemli bir konuysa Sovyetler Birliği'nin kurulması, genişlemesi ve dağılmasıdır. Sovyetler Birliği dünyayı hem savaşlar anlaminda, hem siyasi yönetimler anlaminda hem de ekonomik anlayış anlamında önemli ölçüde etkilemiştir. Sovyetler Birliği'nin dağılması Türk cumhuriyetlerinin geleceğinde de büyük değişiklik yaratmıştır. Çağdaş Türk ve Dünya Tarihi programıla Uzak Doğu ve Afrika Kitası'ndaki tarihsel olaylara da yer verilmiştir. Tarih ders kitabında yer alan başka önemli bir konuysa küreselleşmedir. Küreselleşme teknolojiyle desteklenerek insanların hayatını kolaylaştırmıştır bununla beraber insanoğlu küresel sorunlarla da karşı karşıya kalmıştır.

Tarihî bilgilerin hangisinin ne kadar sürede öğrencilere aktarılacağı ders programlarında sunulmaktadır. Ancak bu konuların aktarıminda en önemli unsur tarih öğretmenidir. Tarihsel konuların öğrencilere aktarımında öğretmenin konulara yüklediği tarihsel önemin etkisi büyüktür (Levstik, 2008: 52).Bununla beraber hangi olayın daha fazla tarihsel önem taşıdı̆̆ına karar vermek çok kolay olmayabilir. Kimi tarihçilere göre önem taşıyan olaylar insanlara ve onların yaşadı ̆̆ı çevreye çok uzun süreli etki eden olaylardır. Bu değerlendirmeye göre I. Dünya Savaşı, Fransız Devrimi, büyük politik, ekonomik ve askeri liderler çok büyük tarihsel öneme sahiptir. Bununla beraber son yıllarda da sosyal tarih önem kazanmıştır. Örneğin "aşağıdan tarih" diye nitelendirilen sıradan insanların tarihi de önem kazanmıştır. Bunun yanında kadın tarihiyle ilgili olaylar, işçi tarihiyle ilgili olaylar bu duruma örnektir. Özel inceleme alanı olarak sıradan insanların tarihi on sekizinci yüzyıldaki kitle hareketlerinin tarihiyle başlamaktadır. Bu tarih anlayışının ilk temsilcisinin de Michelet olduğu kabul edilmektedir. Bunun yaninda Georges Lefebvre de sıradan insanların yaşamına özel önem yüklemiştir. "Büyük Korku" adlı yapıtında Fransız egemen sınıfının değil Fransız halkının tarihine yönelmiştir ( Hobsbawn, 1999: 310). Anlatılanlara ek olarak şunu da söylemek gerekir ki bir olayın tarihsel öneme sahip olabilmesi için geçmişte yaptığı büyük etkisinin günümüze de yansıması gerekmektedir. Tarihsel bilgiler onları analiz edebilen ve neden önemli olduklarını açıklayabilen tarihçiyle anlam kazanmaktadır (Seixas, 1997: 120). Sadri Maksudi Arsal Birinci Türk tarih Kongresi'nde tarihin şekillenmesinde en önemli olan konular1 şöyle sırlamıştır: Fiziki ve coğrafi etkenler, manevi etkenler, büyük idealler, fetih ve göçler, ilerleme yasası, iktisadi etkenler, halk, büyük şahsiyetler. Öğrencilerin olaylara yükledikleri tarihsel önemin derecesi ise onların din, mensup olduğu etnik kimlik, ülkesi ve yaşadığı coğrafya gibi pek çok değişkene bağlı olabilmektedir. Levstik (2008) “Geçmiş bilgisini değerli kılan nedir? adlı yazısında şimdi tarihsel öneme sahip bir olay gelecekte de aynı öneme sahip olup olamayacağının da başka bir 
tartışma konusu olduğunu belirtmiştir. Çünkü değişimlerle beraber tarihsel olaylara yüklenen önem azalıp artabildiği de bir gerçektir. Tarihsel önem pek çok araştırmaya konu olmuştur.

Levstik (1997-1998) ABD’de ilköğretim ikinci kademe öğrencileriyle ergenlerin kadın haklarının tarihsel öneminin algısına yönelik çalışma yapmıştır. Çalışmada konuyla ilgili fotoğraflar kullanılmış, bu fotoğraflardan hareketle öğrencilerden kadın hakları konusunda görüşleri alınmıştır. Çalışmada öğrencilere kadın haklarıyla ilgili hangisinin en önemli olduğu sorulmuştur. Ayrıca kız öğrencilere sizce erkek öğrenciler hangi resmi seçer? Erkek öğrencilere de sizce kizlar hangi resmi tercih eder sorusu sorularak erkek ve kız öğrencilerin birbirlerine bakış açıları da öğrenilmeye çalışılmıştır. Araştırmanın sonucuna bakıldığında öğrenciler birinci sırada kadının sembol olduğu 15 Ekim 1791 tarihli haklar Bildirgesini seçmiştir. Öğrenciler ikinci sıradaysa "sivil haklar" konusunu seçmiştir. Bu hareket İkinci Dünya Savaşı'ndan hemen sonra başlamıştır. Öğrencilere gösterilen bu fotoğrafta Martin Luther King siyahîlerle beraber bir gösteridedir. Öğrenciler üçüncü sıradaysa kadınların oy hakkıyla ilgili konuyu seçmiştir. Bu konuda bir kadının oy kullandığı resimle beraber sunulmuştur.

Peter Sexias (1994) yılında Kanadalı öğrencilerle tarihsel önem konusunda çalışmıştır. Çalışmaya 38 öğrenci katılmıştır. Çalışmada 14 öğrenciyle de görüşme yapılmıştır. Öğrenciler kendilerine sunulan 29 tarihsel olaydan "dünya savaşlarını" ilk sırada tercih etmiştir. Öğrenciler ikinci sırada Amerika Kıtası'nın bulunmasını önemli olarak seçmiştir. Üçüncü sıradaysa Komünizmin yükselişi ve düşüşü en önemli tarihsel olay olarak tercih edilmiştir. Öğrenciler dördüncü sırada Kanada'nın bağımsız olmasını beşinci sıradaysa Fransız Devrimi'ni önemli olarak tercih etmiştir. Bu çalışmada öğrencilerin tarihsel önemle ilgili bir konu seçerken yerel olaylardan ziyade insanlığın tümünü ilgilendiren konuları tercih ettiği görülmüştür.

Levstik (2000) 48 öğrenci, 20 öğretmen adayı, 12 öğretmenle Amerika Birleşik Devletleri tarihindeki olayların tarihsel önemine ilişkin çalışma yapmıştır. Çalışmada Amerikan tarihiyle ilgili resimler kullanılmış bu resimlerden hareketle tarihsel olaylarla ilgili öğrencilerle görüşme yapılmıştır. Görüşmede öğrenciler genellikle ABD'nin ulus olma süreci, göçmenler, sivil haklar, kadın hakları, ayrımcılık gibi konulara yoğunlaşmıştır. Ekonomik kriz konusu ise sadece bir öğrencinin dikkatini çekmiştir.

Yeager, Foster ve Greer (2002) yılında ABD ve İngiltere' de 44 öğrenciyle çalışmıştır. Çalışmada öğrencilere 20. yüzyılın en önemli 10 olayını yazmaları, önem derecesine göre 1 ile 10 arasında puan vermeleri istenmiştir. Buna ek olarak öğrencilere 47 tarihsel olayın yer aldığı bir liste de verilmiş Yirminci yüzyılın en önemli olayını seçmeleri istenmiştir. Öğrenciler yine tarihsel olayları önem sırasına göre 1-10 puan arasında sıralayacaktır. İngiliz öğrenciler en önemli olay olarak İkinci Dünya Savaşını, ikinci sırada I. Dünya Savaşı'nı, üçüncü sıradaysa uzaya uydu gönderilmesini, dördüncü sıradaysa Prenses Diana'nın ölümü seçilmiştir. İngiliz öğrenciler kendi oluşturdukları listedeyse kendi yaşamlarına ait özel olayları da tarihsel öneme sahip olay seçmişlerdir.

ABD'li öğrenciler, tarihsel öneme sahip olan en önemli on olay arasında İkinci Dünya Savaşı'nı birinci sırada, I. Dünya Savaşı'nı ikinci sırada, büyük bunalımı üçüncü sırada, Aya ayak basma olayını ise dördüncü sırada tarihsel öneme sahip olaylar olarak seçmiştir. Araştırmacının verdiği listede tarihsel öneme sahip olan en önemli üç olay olarak İkinci Dünya Savaşı, Büyük bunalım, Aya ayak basma olayı seçilmiştir. Araştırmacılar seçilen öğrencilerle bahsedilen seçimlerin neden yapıldığını anlamak için görüşme yapmıştır. 
Barton (2005) Kuzey İrlanda'da 12-17 yaşındaki 40 öğrenciyle çalışma yapmıştır. Öğrencilerin yarısı Katolik yarısı ise Protestan öğrencilerden seçilmiştir. Kuzey İrlanda Katolik ve Protestan topluluk arasında iç savaşlarla bölünmüş ve yıpranmış bir konuma sahiptir. Öğrencilere 1500 yıllık süreci kapsayan görseller gösterilmiş ve tarihsel açıdan en önemli 10 olayı seçmeleri istenmiştir. Daha sonra seçilen 10 resimden hangisinin en önemli olduğunun seçilmesi istenmiş ve neden bu resim seçildiğine yönelik yarı yapılandırılmış görüşme yapılmıştır. Çalışmanın sonucu değerlendirildiğinde erkek öğrenciler daha çok politik konulara ve çatışmalara yoğunlaşmıştır kız öğrencilerse eşitlik ve diğer insanlara yardımla ilgili resimlere yoğunlaşmıştır. Çalışmada en önemli tarihsel olay olarak ölümlerin ve zorlukların yaşandığ Katolik Protestan çatışmasıyla ilgili resmi, eşitlik, adalet ve temel haklarla ilgili talepleri de üçüncü sırada önemli olay olarak seçmiştir. $\mathrm{Bu}$ çalışmada Kuzey İrlanda'da yaşanan iç çatışmaların öğrencilerin tarihsel önem konusunda düşüncülerine önemli etki yaptığı sonucuna ulaşılmıştır.

Terzian (2007) Latin kökenli 70 lise öğrencisiyle ABD tarihiyle ilgili tarihsel önem hakkında çalışma yapmıştır. Çalışmada öğrenciler ABD tarihinde en önemli olay olarak birinci sırada İç Savaşı, ikinci sırada İkinci Dünya Savaşı'nı, üçüncü sıradaysa Amerikan Devrimi'ni seçmiştir. Öğrenciler en önemli kişi olarak birinci sırada George Washington, ikinci sırada Abraham Lincoln üçüncü sıradaysa Thomas Jefferson'u seçmiştir. Öğrenciler en önemli kanun olarak da birinci sırada anayasayı, ikinci sırada Bağımsızlık Bildirgesi'ni, üçüncü sıradaysa Haklar Beyannamesi'ni seçmiştir.

Barton ve Levstik (2008) ABD'de tarihsel önem hakkında öğrencilerle çalışma yapmıştır. Çalışma Kentucky Eyaleti'nde 48 öğrenciyle ger- çekleştirilmiştir. Öğrencilere son beş yüz yıllık ABD tarihiyle ilgili resimler zaman şeridi halinde gösterilmiş ve en önemli tarihsel olayı anlatan sekiz resmin seçilmesi istenmiştir. Daha sonra öğrencilerle seçimleriyle ilişkin görüşme yapılmıştır. Araştırmanın sonuçlarına bakıldığı zaman öğrenciler ilk sırada ABD halkına daha çok özgürlük tanıyan haklar beyannamesini ve ABD'nin İngiltere'den ayrılarak bağımsızlığını ilan etmesini aynı oranda en önemli tarihsel olay olarak seçmiştir. Öğrenciler ikinci sırada köleliğin kaldırılmasını tercih etmiştir. Öğrenciler üçüncü sıradaysa İkinci Dünya Savaşı'nı tercih etmiştir.

Lin ve diğerleri (2009) 12 ülkede yaptıkları çalışmada katılımcılara son bin yılın en önemli olayı ve iyi ya da kötü olarak dünyayı etkileyen kişi sorulmuştur. Çalışmada en önemli olay olarak İkinci Dünya Savaşı seçilirken en etkili isim ise Hitler olmuştur. Bu çalı̧̧manın Türkiye örneğiyse Başkent Üniversitesi'nde yapılmıştır. Türk öğrenciler en önemli tarihsel olayı I. Dünya Savaşı olarak seçmiştir. Kurtuluş Savaşı ikinci sırada, İkinci Dünya Savaşı üçüncü sırada, İstanbul'un fethiyse dördüncü sırada seçilmiştir. Çalışmada Türk katılımcılar Kemal Atatürk'ü birinci sırada, Hitleri ikinci sırada, II. Mehmet'i üçüncü sırada, Einstein'i dördüncü sırada en etkili tarihsel aktör olarak seçmiştir.

\section{Amaç}

Çalışmanın literatürü değerlendirildiğinde yabancı ülkelerde tarihsel önem konusu akademik çalışmalara konu olurken Türkiye'de tarihsel önem konusunda uygulamalı araştırmaların eksik olduğu görülmektedir. Akademik yazılarda tarihi olayların önemine yönelik eserler verilmişken öğrencilerin ve öğretmen adaylarının tarihi olayların önemini nasıl alg1ladığına yönelik uygulamalı çalışmaların eksik olduğu tespit edilmiştir. Bu düşünceden yola çıkılarak Kafkas Üniversitesi Fen-Edebiyat Fakültesi tarih bölümünde öğrenim gören 
öğrencilerin Çağdaş Dünya Tarihi konularının tarihsel önemine yönelik görüşlerini tespit edilmeye çalışılmıştır. Bunun yanında Çağdaş Türk ve Dünya Tarihi ders kitabı bu alanda ilk kitaptır. Elde edilen veriler bu kitapta yer alan konulara üniversite öğrencilerin yaklaşımı hakkında da ipucu verecektir.

\section{YÖNTEM}

Çalışmanın bu bölümünde araştırma modeline, çalışma gurubunda yer alan öğrencilerin cinsiyet ve sınıf düzeylerine ilişkin sayısal veriler yer alacaktır.

\section{Araştırma Modeli}

$\mathrm{Bu}$ araştırmanın yöntem nitel bir araştırmadır. Araştırma deseni durum çalışmasıdır. Durum çalışmaları nicel ve nitel yaklaşımla yapılabilir. Her iki yaklaşımda da amaç belirli bir duruma ilişkin sonuçları ortaya koymaktır (Yıldırım ve Şimşek, 2006: 77). Çağdaş Türk ve Dünya Tarihi ders kitabı incelenmiş ve üniteler tespit edilmiştir. Ünitelerde anlatılan konular tematik olarak belirli konu başlıkları altında toplanmıştır. Bu konu başlıkları tarih eğitiminde uzman olan iki akademisyene danışılmıştır. Uzmanlardan alınan dönütler neticesinde bu ders kitabında yer alan tarihsel olaylar dokuz kategori altında toplanmıştır. Bu kategoriler: Savaşlar, Sovyetler Birliği'nin Kuruluşu ve DağılmaS1, 1929 Dünya Ekonomik Krizi ve Diğer Krizler, Uluslararası Kuruluşların Oluşması, Asya ve Afrika'da Yeni Devletlerin Oluşumu, Soğuk Savaş Dönemi Mücadele ve Savaşlar, İcatlar İle Teknolojik ve Bilimsel Gelişmeler, Küresel
Sorunlar, Moda, Müzik, Sinema ve Sporun Küreselleşmesi. Bu kategoriler öğrencilere bir doküman halinde sunulmuştur. Öğrencilere kendilerine verilen kategorilerden hangisinin dünya tarihi açısından en önemli olduğunu ve sebebini yazmaları istenmiştir.

\section{Çalışma Grubu}

Bu çalışma 2013-2014 yılının güz döneminde Kafkas Üniversitesi Fen Edebiyat Fakültesi Tarih bölümünde uygulanmıştır. Çalışmada amaçlı örnekleme yöntemlerinden ölçüt örnekleme yöntemi kullanılmıştır. Bu örnekleme yöntemindeki temel anlayış önceden belirlenmiş bir dizi ölçütü karşılayan bir durum çalışmasıdır (Yıldırım ve Şimşek, 2006: 112). Çalışmada tarih bölümünün tercih edilme nedeniyse tarih bölümü öğrencilerinin dünya tarihi ile ilgili konularda bilgi düzeyi ve farkındalık düzeyinin yüksek olduğu düşünüldüğü için olmuştur. Buna ek olarak tarih bölümü öğrencileri aynı zamanda tarih öğretmen adayı konumundadır. Ortaöğretimde okutulmakta olan Çağdaş Türk ve Dünya Tarihi dersi gelecekte bu öğretmen adayları tarafından öğretilecektir. Çalışmaya 198 öğrenci katılmıştır. Çalışma grubu ile ilgili bilgiler Tablo 1'de verilmiştir. Öğrencilerin cevaplarından örnekler sunulurken Erkek öğrenciler (E) Kadın öğrenciler (K) harfleriyle gösterilmiştir. Ayrıca öğrencilerin hangi sınıftan oldukları da bilgisi de eklenmiştir.

Tablo 1. Katılımcılara Ait Bilgiler

\begin{tabular}{lccccccc}
\hline & \multicolumn{4}{c}{ Sınıf } & \multicolumn{3}{c}{ Cinsiyet } \\
Birinci & İkinci & Üçüncü & Dördüncü & Belirtilmemiş & Erkek & Kadın & Belirtilmemiş \\
\hline 36 & 43 & 44 & 65 & 10 & 85 & 112 & 1 \\
\hline $\begin{array}{l}\text { Tablo 1'e bakıldığında en fazla katılımcı grubu } \\
\text { dördüncü }\end{array}$ & $\begin{array}{l}\text { madnı kadın öğğrenci sayısı erkek öğrencilerden } \\
\text { daha fazladır. }\end{array}$
\end{tabular}




\section{BULGULAR}

Çalışmanın bu bölümünde öğrencilerin verdikleri cevapların frekansları, yüzdelik oranları ve öğrencilerin verdikleri cevaplardan örnekler sunulacaktır.

Tablo 2. Tarih bölümü öğrencilerin tarihsel önem açısından sıraladıkları konuların frekans ve yüzdelik oranları

\begin{tabular}{lccc}
\hline Önem sırası & Konular & F & \% \\
\hline 1 & Savaşlar & 92 & 46.4 \\
2 & Küresel sorunlar & 23 & 11.6 \\
3 & İcatlar ile teknolojik ve bilimsel gelişmeler & 20 & 10.1 \\
4 & Soğuk Savaş dönemi mücadele ve savaşlar & 19 & 9.5 \\
5 & Uluslararası kuruluşların oluşması & 13 & 6.5 \\
6 & Sovyetler Birliği'nin kuruluşu ve dağılması & 9 & 4.5 \\
7 & Asya ve Afrika'da yeni devletler'in kuruluşu & 8 & 4.0 \\
8 & Moda, müzik, sinema ve sporun Küreselleşmesi & 8 & 4.0 \\
9 & 1929 Ekonomik krizi ve diğer ekonomik kirizler & 6 & 3.0 \\
& Toplam & 198 & 100
\end{tabular}

1.Savaşlar: $\mathrm{Bu}$ kategori Yirminci Yüzyılda dünyada meydana gelmiş büyük savaşları içermektedir. İki dünya savaşı, İspanya iç Savaşı, Arap-İsrail savaşları, Körfez savaşları, Arap Baharı ve Arap coğrafyasında yaşanan savaşlar bu kategoriyle ilişkilidir. Tablo 2 yorumland1ğında tarih bölümü öğrencilerinden en fazla kişi savaş konularını dünya tarihi açısından en önemli olarak ( \% 46.4) ilk sırada tercih ettikleri anlaşılmaktadır. Öğrencilerin tercih nedenine ilişkin açıklamalardan bazı örnekler verilmiştir. Öğrencilerin cevapları değerlendirildiğinde öğrenciler savaşların dünyayı diğer olaylara kıyasla daha fazla şekillendirdiğini söylemiştir. Öğrencilerin özellikle savaşların sonuçlarına yoğunlaştıkları da görülmektedir.

(E-3). Gelecekteki bir tarih öğretmeni olarak söylüyorum ki gerek öğrencilerin gerekse yetişkin insanlar için en önemli olan şey savaşlardır....
(E-4). I. Başlı̆̆ı seçiyorum. Çünkü özellikle Birinci ve Íkinci Dünya Savaşlar milyonlarca insanın ölümüne neden oldu, smırlar değişti, Güneydoğu Asya'da, Vietnam'da ve Ortadoğu gibi bir çok bölgede siyasi istikrarsızlıktan dolayı günümüzde hala çatışmalar devam etmektedir.

(E-2). Savaşlar, doğal afetlerin geçmişte yapamadı$\breve{g} l$, gelecekte yapamayacağ maddiyatında ve maneviyatında büyük tahrip yaratmıştır.

(E-3). Niçin Savaş? Yillarca devletlerarası süren politikalar olsun, mücadeleler olsun ve bundan en fazla etkilenen, zarar gören yine insanoğlu olmuştur: Ör. ABD'nin atom bombası.

(E-1). Savaşlar her zaman dünya tarihi yazmıştır. Birinci ve İkinci Dünya savaşlarn dünya üzerinde büyük ölçüde yaşandı̆̆ı için dünya tarihi açısından önemlidir.... 
(E-3). I. Kategori benim için önemli çünkü savaşlar insanlık için hatta tüm canliları kapsayan bir olaydır. Milletlerin birbirini yok etmesi güçlünün güçsüzü ezmesi, zalimin zulmünü devam ettirmesi hepsi savaşlar başlığı altındadır. O yüzden önemlidir.

(E-3). Savaşlar devlet hakkında birçok bilgi verir. Gücünü, siyasal olayları toplumsal hayatları, toplumsal hayatları savaşlarla belirlenebilir....

(E-3). En önemlisi savaşlardır. Çünkü savaşlar sosyal yapıyı, ekonomik yapıyı, devletlerin işleyiş düzenini değiştiren bir olaydır.

(K-1). I. Ve II. Dünya savaşlarmı bilmek bence daha önemli çünkü savaşların neden, nasıl çıktı̆̆ını, milletimizden neler alıp neler getirdiğini bilmek önemli onun için savaşların anlatılması daha iyi olur.

(K-2). Savaşlar her zaman bir toplumun ya da ülkenin kaderini değiştirecek güce sahiptir. Bu savaşlar bazı güçlü devletleri ortadan kaldırmakla beraber bazı küçük devletlerin kurulmasını să̆lamiştır....

(K-3). Çünkü belki bir ülkenin kurulmasına, belki de bir insanlığın yok oluşuna sebeptir....

(K-4). 1. Kategori diyorum. Çünkü yeni oluşan olaylar açısından bugünkü Arap- İsrail savaşlarında Türkiye'nin durumu ırak'ta oluşan çatışmaların Türkiye'ye yansıması, burada olan savaşların hepsinin Türkiye'nin durumunu etkileyeceğini ve oluşacak çatışmalardan her an birisine girmesi açısından önemli buluyorum....

(K-2). Savaşlar tüm dünyayı siyasi ve sosyal sebeplere yön verir. Insanoğlunun kültürel güçlü yönlerine yön verir. Insan haklarının ortaya çıkması ve bazı gelişmelere önem verir....

(K-3). Savaşlar önemlidir çünkü insanlığın gelişimini etkileri yani savaşlar yeryüzünde kurulan devletlerin yerini tarihini büyük ölçüde etkilemektedir....
(K-3). Savaşlar, insanlık tarihi açısından en önemli kategorinin başında geliyor. Savaşlar dünya üzerinde geniş bir coğrafyada yayılabilmenin ön koşuludur. Savaşlar kültür alış verişi sağlayan, yeni düşüncelerin, yeni akımların, yeni araç ve gereçlerin ortaya çıkmasına neden olur.

2. Küresel sorunlar: Bu kategori doğal ve insan kaynaklı sorunlardır. Pek çok insanı etkilemiş olan AIDS, kuş gribi, kanserin yaygınlaşması gibi hastalıkların yanında depremler, nükleer kazalar, su kaynaklarının azalması ve açlık gibi konuları kapsamaktadır. Tarih bölümü öğrencilerinin ikinci sırada seçtikleri bu kategoriye ilişkin verdikleri cevaplardan bazı örnekler aşağıda verilmiştir. Tarih bölümü öğrencilerinin açıklamaları değerlendirildiğinde küresel sorunların insan sağlığını tehdit ettiğine yönelik açıklamaların olduğu göze çarpmaktadır. Kimi öğrencilere göreyse küresel afetlerin olmasında Allah'ın takdiri vardır ve insanlar bu afetlerden ders çıkarmalıdır. Küresel sorunlar konusu tarih programına yeni girmesine rağmen öğrenciler tarafından ikinci sırada önemli görülmüş̧ür.

(K-4). 8. Maddeyi seçtim. Çünkü bir devlet bir millet ne kadar güçlü, yenilmez üstün olsa da doğal ya da beşeri faktörler bu gücü üstünlüğü yıkar yerle bir eder....

(K-1). Küresel sorunlar günümüz ilgilendiren en önemli olayların başında gelir. Dünyamıza ve insanlığa daha faydalı olacağını düşünüyorum. Yeni metotlarla ve öğrencilere dünyamızın içinde bulunduğu ve bulunacağı sorunlar anlatılarak bu sorunlara çareler bulunması daha iyi olur.

(K-2) Küresel sorunların oluşmasıyla birlikte bunlar günümüzde giderek artmaktadır. Bu savaşlar bugünü ve geleceğimizi tehdit ettiğinden benim için en önemli sorun budur. Bu gibi sorunlar dünyayı tehdit ettiğinden çözümler üretilmelidir. 
(E-2). Insanlık nüfusu arttıkça; hastalık, çevre kirliliği, ölüm doğal kaynakların yanlış kullanılması sonucu oluşan doğa olayları ve yıkım. Yanlış politikalar yüzünden milyonlarca ă̆açlar kıyıma ŭgramakta, betonarme binalar çoğalmakta, taban suyunun bilinçsizce kullanılması sonucu çöküntü depremlerinin oluşması, doğal parklarm yeterli sayıda olmaması yüzünden bazı hayvanların nesli tükenmesi, ahlaksal çöküntü ve buna bağlı olarak zührevi hastalıkların çoğalması anızın yakılıp topră̆ın kısırlaştırılması vs...

(E-2). Küresel sorunlar, kuş gribi, kanser, açlik vb gibi sorunlar insan sağhı̆̆ını tehdit ettiği için.

(E-4). Açıklama: bu sorunların meydana gelmesinde insanın dünyaya gelişinin asıl vazifesini ihmal ettiğinden dolayı Allah tarafindan kullarını uyarması için vermiştir. Ĕ̆gr masum insanlar bundan etkilenmişse seçmiş günahlarına kefaret olur, eğer zalimler etkilenmişse hak ettikleri cezaları almıştır. Insanlar başlarına gelen musibetten ders alsalar daha iyi olur.

Yukarıda verilen örnekte tarih bölümü dördüncü sınıfta okuyan bir erkek öğrenci küresel afetlerin meydana gelmesini dini bir nedene dayandırmıştır. Bu öğretmen adayına göre insanlar bu afetlerden ders çıkarmalıdır. Bu görüşe göre insanlar ibadetlerini tam olarak yerine getirmemesi cezalandırılmalarına neden olabilir. Öğretmen adayı burada bilimsel nedenler yerine görüşünü inanç sistemiyle ilişkilendirmiştir.

(E-4). Küresel sorunlar günümüzü ilgilendiren ve çok derinden sarsabilecek sonuçlar doğurabilir. Bunlarm bilinmesi daha öncelikli olabilir. Çünkü diğer kategorileri aşă̆ı yukarı birçok ders içinde görüp öğreniyoruz.

3. Ícatlar ile teknolojik ve bilimsel gelişmeler: $\mathrm{Bu}$ kategori bilimsel, teknolojik gelişmeler ve icatlarla ilgili olan bölümdür. İnsanların hayatlarını değiştiren ve kolaylaştıran televizyon, internet ve otomobil gibi araçlar bu kategori içerinde sunulmuştur. Öğrenciler bu kategoriyi üçüncü sırada seçmiştir. Öğrencilerin bu kategorinin önemine yönelik görüşleri aşağıda verilmiştir. Öğrencilerin cevapları değerlendirildiğinde öğrenciler bilimsel yeniliklerin insan hayatını kolaylaştırdığını, bilginin hızla yayılmasını sağladığını, daha iyi bir yaşam sağladığını belirtmiştir. Bu kategoride yer alan konularda yakın zamanda tarih programlarına eklenmesine rağmen öğrenciler tarafından üçüncü kategori de önemli olaylar grubu olarak seçilmiştir.

(K-1). Ícatlar ile teknolojik ve bilimsel gelişmeler bir toplumu ileriye taşıyan önemli bir olgu olduğu için bu kategoride ders verilmelidir.

(K-1). Ícatlar ile teknolojik ve bilimsel gelişmeler sayesinde insanlar dünyanın diğer ucunda olan olaylardan bile çok kısa bir süre içerisinde haberdar olabiliyor. Ĕ̆ger bunlar olmasaydı insanların kendi uğraşları veya farklı dallarda bilgi sahibi olması, yeni fikirleri üretmesi daha zor hatta imkânsız olurdu.

(K-2). Tarihin her çă̆ında teknolojiye ve bilime ihtiyaç duyulmuştur. Teknolojinin ve bilimin gelişmesi tarihi de etkilemektedir. Bir telefonun icat edilmesi ve ya matbaanın icadı dünyayı çok etkilemiştir...

(E-2). Dünyanın gelişmesi, büyümesi için icatlar, teknolojinin yeri vazgeçilmezdir, neden diye soracak olursaniz modern dünyada ülkelerin, milletlerin, gelişmesi teknolojiye bağhdır. ....

(E-2). TV, internet gibi haberleşmeyi üst düzeye çıkaran teknolojik gelişmeler sayesinde toplumsal sinıf ve ırk farklılı̆̆ den daha fazla haberdar olup bu konular hakkında fikirlerini dile getirip ve gerektiŏinde de örgütleşebiliyorlar. Bu şekilde insancıl yaşam için en önemli kaynak olan demokrasi daha doğru yaşanır ve hayat tamamen gerçek halk tarafindan yönetilir...

4. Soğuk Savaş dönemi mücadele ve savaşlar: Bu kategori İkinci Dünya Savaşı'ndan Sovyetler 
Birliği'nin Dağılmasına kadar geçen sürede dünyanın iki kutup halinde çatışma yaşadığı süreci kapsamaktadır. Bu döneme $\mathrm{ABD}$ - SSCB rekabeti, Kore Savaşı, Vietnam Savaşı, Sovyetlerin Doğu Avrupa'da yayılması gibi olaylar damgasını vurmuştur. Bu kategori öğrenciler tarafından dördüncü sırada tarihsel öneme sahip olay olarak tercih edilmiştir. Öğrencilerin bu kategoriyi neden önemli gördüklerine yönelik açıklamalar verilmiştir. Tarih bölümü öğrencileri bu kategoriyi seçme nedenleri olarak dünyanın ABD ile SSCB arasında bölündügünü bu bölünmenin hem geçmişte hem de günümüzde de etkili olduğunu dile getirmişlerdir.

(K-4).Soğuk Savaş dönemi mücadele ve savaşlar yakın tarihimizde meydana gelmiş olup deoletlerin yarattı̆̆ı kutuplaşmalar günümüzde de halen hemen her alanda etkilerini devam ettirmektedir.

(K-3). Bu konularm hepsi önemli konulardir. Fakat soğuk savaş dönemi daha yakın zaman ve dünya tarihi ile daha çok bilgi verilmiş olabilir. Soğuk savaş dönemi hakkında bilgilendirilerek dünyada, Türkiye dışında neler olup bittiğini bilir.

(K-4). Soğuk Savaş döneminin anlatılması gerektiğini düşünüyorum. Sovyet Rusya ve ABD'nin politikalar açısından önemli bir dönem olduğu için...

(E-3). Soğuk Savaş dönemi yakın tarihimizi anlamak ayn zamanda yeniden meydana gelen dünya düzeni içerisinde önemli bir yer almaktadır. Bu dünya güçlerini yakından tanımamızı sağlayarak ayn paralelde içinde bulunduğumuz dünyayı anlamamiza yardımo olacaktır.

(E-3). ABD-Sovyet rekabeti ile dünya batı ve doğu olarak ikiye ayrilmıştır. Burada soğuk harb olarak değgrlendirebiliriz. Blokların birbirine psikolojik, maddi ve manevi üstünlük kurmak için muhteşem mücadeleleri buna en iyi örnektir. .....

(E-2). II. Dünya Savaşı'ndan sonra dünya büyük buhrana girmiştir. Bu buhrandan zararlı çıkan devletlerin yanında karl çıkan devletler de vardır. Bunların başında ABD-SSCB çımışıtır. Bu iki devlet arasındaki siyasi ve ekonomik çekişmeler SSCB'nin yıklmasindan sonra da devam etmiştir. SSCB'nin yerini alan Rusya bu rekabeti devam ettirmiştir. Şu an bile bu iki çekişme sayesinde dünya üzerindeki teknolojik gelişmeler yaşanmasına da sebep olmuştur.

5. Uluslararası kuruluşların oluşması: $\mathrm{Bu}$ kategori Birleşmiş Milletler Örgütü, NATO, UNESCO, UNICEF, AB gibi uluslar arası kuruluşları kapsamaktadır. Bu kuruluşlardan bazıları askeri ittifakları içerirken kimi kuruluşlarda uluslararası yardım örgütleridir. Öğrenciler bu kategoriyi tarihsel öneme sahip olma sırasında beşinci sırada işaretlemiştir. Bu kategoriyi tarihsel olarak en önemli seçen öğrencilerden kimi öğrenciler uluslararası kuruluşların önemli olmasıyla beraber bu kuruluşların görevlerini tamamıla yerine getirmediğini de belirtmiştir.

(E-4). Dünya barışının korunması için önemli kuruluşlardır. Bu kuruluşlarla birlikte savaşlarm önüne geçilmeye çalışılmıştır....

(E-4). Uluslararası kuruluşların oluşturulması insanlık tarihi açısından önemli bir kuruluş olarak değerlendiriyorum. Dünyada meydana gelen savaşlar, ekonomik krizler, toplumsal olaylar açısından önemli kuruluşlardır. Ancak bu kuruluşların yeteri kadar duyarlı olduğunu düşünmüyorum...

(E-4). Bu kuruluşların kurulması önemli hem yeni savaşların çıkmasın engelliyor hem de birlik, ittifakların kurulmasını sağlamıştır. Bana göre bu örgütler yeni savaşların çıkmasını büyük ölçüde engellemiştir.

(K-4). I. Dünya Savaşı'ndan itibaren temeli oluşturulmuş olan cemiyetlerin şu anda görüldüğ̈̈ kadarıyla tarafsiz davranmayarak binlerce insanın ölmesine, yok olmansa göz yumuyorlar. Bence bu kurumların artık dünya tarihinde işlevini yerine getirmemesinin en güzel örneğ i Filistin, Suriye, Misır gibi Ortadoğu ülkelerin birbirine girmesi ve buna 
seyirci kalmasıdır. Araya gelerek örgütler ve kuruluşlar kurarak ülkelerin ve milletlerin hakların ve güvenliklerini savunması açısından önemlidir....

\section{Sovyetler Birliği'nin kurulması ve dă̆ılması:} $\mathrm{Bu}$ kategori Sovyetler Birliği kurulurken ve dağılırken yarattığı etkiyle ilişkilidir. Bolşevik Devrimi, Komünist sisteme göre ekonominin yapılanması, SSCB yıkılırken yaşanan savaşlar, Türk Cumhuriyetlerinin bağımsız olması bu kategoriyle bağlantılıdır. Sovyetler Birliği'nin kurulması ve dağılması tarihsel öneme sahip olarak altıncı sırada seçilmiştir. Bu kategoriyi tarihsel olarak en önemli seçen öğrencilerin görüşlerinden örnekler aşağıda verilmiştir. Öğrenciler Sovyetler Birliği ile dünyada ekonomik, sosyal ve siyasal seçeneklerin oluştuğunu dile getirmiştir.

(E-4). Sovyetler Birliği'nin kurulmasını ve dă̆glması seçtim. Çünkü bu devletin kuruluşu ile dünyaya yeni bir denge unsuru gelmiştir. Farkl milletler bu birliğe katılmıştır. Fikir akımları oluşturmuştur. ABD'nin karşısındaki dengeleyici unsur olmuştur. Çöküşünden sonra ise yeni devletler ortaya çıkmıştır. Yeni düzen oluşmuş ve kapitalist sistemin daha ă̆ır bastığ̊ bir yapı oluşmuştur. ABD bir süreliğine rakipsiz kalmıştır.

(E-1). İlgi alanım olduğu için ve diğer arkadaşların da ilgi duyup zevkle dinleyecekleri bir konu olduğunu düşündü̆̆̈̈m için.

(E-2). Sovyetler rejimi ile birlikte dünya yeni bir rejim anlayışının ortaya çıkması, yıkıldıktan sonra bile ardillarını dünya siyasetinde rolleri ve ayrica ABD'nin dünya düzeninde rakipsiz kalması gibi olaylar hem Ortadoğu hem de dünya tarihi açısından önem arz etmektedir. Ayrica dikkatlice incelendiğinde şu anki Rusya Devleti'nin, SSCB'den farklı bir politika izlemediğini görürüz.

(K-3). ABD'nin rakipsiz kalmasi, AzerbaycanErmenistan savaşları ve diğerleri sınır sorunları ortaya çıkardı. Bu sınır sorunları Türkiye Cumhuriyeti'nin kısıtlanmasına yer yer de Türkiye Cum- huriyeti'ne de savaş açılma riskini ortaya çıkardı. Bunların neden meydana geldiğini, Türkiye Cumhuriyeti'nin durumunu lisedeki arkadaşların bu ders içinde öğrenmeleri gerektiğine inanıyorum.

\section{Asya ve Afrika'da yeni devletlerin oluşması:} Bu kategori Afrika ve Asya'da sömürgeci yönetimlerin kalkmasıyla beraber bağımsızlığına kavuşan devletlerle ilgilidir. Bunun yanında Hindistan, Pakistan, Çin Halk Cumhuriyeti gibi güçlü devletlerin kuruluşu da bu kategoriyle bağlantılıdır. Tarih bölümü öğrencileri bu kategoriyi sekizinci sırada tercih etmiştir. $\mathrm{Bu}$ kategoriyi en önemli olarak seçen öğrencilerin açıklamalardan örnekler sunulmuştur. Öğrenciler Asya ve Afrika'da sömürge altında yaşayan devletlerin bağımsız olmalarının değerini vurgularken sömürgeciliğin acımasızlığını da dile getirmiştir.

(E-4). Asya ve Afrika'da yeni devletlerin kurulması bir nebze de olsa sömürgeciliği ortadan kaldırmıştır. Halklar bağımsızlıklarını kazanmışlardır ve özgürlüklerine kavuşmuşlardır.....

(K-4). Sömürgecilik her devlet için hoş olmayan ve yıpratıc bir kavramdır. Bunun engellenmesine yönelik bilgi alınabilir....

8. Moda, müzik, sinema ve sporun küreselleşmesi: Bu kategori moda, müzik, sinema ve spor gibi faaliyetlerin ulusal sınırları aşarak uluslar arası etki yaratmasıyla ilişkilidir. Bu faaliyetler küreselleşme kavramına doğrudan katkı sağlamaktadır. Tarih bölümü öğrencileri bu kategoriyi sekizinci sırada seçmiştir. Bu kategoriyi en önemli gören öğrencilerin cevaplarından örnekler aşağıda verilmiştir. Öğrenciler küreselleşmeyle beraber toplumların birbirlerini daha iyi tanıdığını dile getirmiştir.

(K-3). Bu kategoriyi seçmemin nedeni dünyada yaşanan savaş, deprem, ekonomik krizden bunalan insanların bu tip uğraşlarla vakit geçirip iyi şeyler yapmaya hakkı da olması lazım... 
(K-

4).Kültürlerinilerleyebilmesiiçininsanlı̆̆ınbirbirinit anımasındaönemlibiryeriverdirsanatın....

(E-3).Moda, müzik, sinema ve sporun küreselleşmesi; hem kültür hem de dünya hakknda ülkeler hakkında bilgi sahibi olunmasını sağlar...

(E-2). Evrensel barışa yönelik yapılan olimpiyatlar iki ülke arasındaki sicak gelişmeler için yapılan Eurovision yarışması dostlukların pekişmesi için barışın korunması için evrensel bir kardeşlik çerçevesi oluşması için kültürel çalışmalardır.

\section{1929 Dünya Ekonomik Krizi ve diğer ekono-} mik krizler: Bu kategori ekonomiyle ilişkilidir. Dünyadaki ekonomik krizlerin ve ekonomik sorunların öğrenciler tarafından ne kadar önemli görüldüğgüle ilişkilidir. Bu kategoriyi en önemli tarihsel olay olma bakımından en az öğrenci tercih etmiştir. Bu kategoriyi tarihsel açıdan en önelmiş olay olarak seçen öğrencilerin cevaplarından örnekler aşağıda verilmiştir.

(E-4). Ne için seçtĭgimi sorarsanı tarih boyunca devletlerin dini olmamıştır. Hep gayeleri ekonomik çıkarlar ve şahsi menfaatlerini hep ön sirada yer almıştır....

(K-2). 1929 ekonomik krizi ve diğer krizler: Krizlerin ülkelerin geleceğini nasıl tehdit edeceği için bu krizleri gerekli önlemlerin alınması açısından bilinmesi gerekir. Ekonomi bir ülkenin gelişimi açısından önemlidir.

(K-3). Ekonomik Kriz dünyanm neresinde hangi toplumda ne zaman yaşanırsa yaşansin devletin, hükümetin her anlamda çok fazla etkilediği durumdur. Borsanın değişmesi, enflasyon oranları, bunlarin halk üzerindeki etkileri her zaman kötü sonuçlar doğurmuştur...

\section{TARTIŞMA VE SONUÇ}

Tarihsel bir olayın geleceğe ulaşmasında o bilginin insanların ilgisini çekmesi, tarihçiler ve diğer bilim adamları tarafından önemsenmesi gerekmektedir. $\mathrm{Bu}$ nedenler tarih konularına öğretmenlerin ve öğrencilerin yükledikleri değer önemlidir. Son yıllarda tarihsel önem konusuyla ilgili çalışmaların da yoğunlaştı̆̆ 1 görülmektedir. Dünya üzerinde yaşanan hızlı değişim insanların ilgilerini, ihtiyaçlarını sürekli değiştirmektedir. İnsanlar her değişliğe uyum sağlamak amacıyla yeni bilgiler edinmek zorundadır. Bu değişimler eğitim sistemine de yansıyarak program değişikliğine neden olmaktadır. Bu değişimden tarih bilimi de önemli ölçüde etkilenmektedir. Tarih programlarında yaşanan son değişiklikler bu durumun açık kanıtıdır. Çağdaş Türk ve Dünya Tarihi dersinin ortaöğretim tarih ders programina eklenmesiyle beraber yaklaşık olarak bir asırlık olaylar bu ders programının içerisine dahil edilmiştir. Yazılan ders kitabı da yüzyıllık yoğun bilgiler içermektedir. Çünkü 20. yüzyıl hem siyasal, hem bilimsel hem de ekonomik çok önemli değişimlere tanıklık etmiştir. Bununla beraber Uzak Doğu ve Afrika Kıtası'ndaki tarihsel olaylara yer verilmesi dünya tarihi öğretimi açısından önemli bir gelişmedir Böylece dünya tarihi anlatımı Avrupa merkezli olmaktan bir nebze olsun kurtulmuştur. Bu durum aynı zamanda Türk tarihçiliğinin ufkunun da aç1dığına işaret etmektedir. Çalışmanın sonuçları değerlendirildiğinde üniversite öğrencileri aynı zamanda da tarih öğretmeni adaylarından fazla sayıda kişi tarihsel öneme sahip ilk tercihlerinin savaş konularının olduğu görülmektedir. Tarih ders kitaplarından savaş konularının azaltılması yönündeki tavsiyelere ya da savaş konuları tarih ders programlarında geri plana atmaya yönelik düşüncelerin çok fazla karş1lık bulmadığı görülmektedir. Öğrenciler savaş konularına en fazla tarihsel önem yüklemiştir. Sexias (1994) yılında yaptığı çalışmada öğrenciler yirmi dokuz tarihsel olaydan dünya savaşların ilk sırada tarihsel öneme sahip olay olarak tercih etmişlerdir. Yeager, Foster ve Greer (2002) yılında yaptığı çalışmada Amerikan ve İngiliz öğrenciler dünya savaşlarını tarihsel 
öneme sahip en önemli olay olarak tercih etmiştir. Bu üç çalışma öğrencilerin savaş konuların öğrenmeye değer verdiğini ortaya koymuştur.

Üniversite öğrencileri tarihsel öneme sahip ikinci kategori olarak küresel sorunlar kategorisini seçmiştir. Öğrenciler küresel sorunların insan yaşamını tehdit ettiğine yönelik açıklamalar yapmıştır. Öğrenciler üçüncü sırada ise teknolojik ve bilimsel gelişmeler kategorisini seçmiştir. Yeager, Foster ve Greer (2002) yaptıkları çalışmada ABD'li öğrencilerin insanoğlunun aya ayak basma olayını üçüncü sırada tarihsel öneme sahip olay olarak tercih ettiği görülmüştür. Bahsedilen iki çalışmadan hareketle öğrencilerin bilimsel ve teknolojik gelişmeleri en önemli tarihsel olay olarak seçmeseler de ilk üç sırada tarihsel öneme sahip olay olarak tercih etmişlerdir.

Öğrenciler dördüncü sırada Soğuk Savaş dönemi mücadele ve savaşlar kategorisini seçmiştir. Soğuk Savaş döneminde her ne kadar ABD ve SSCB arasında doğrudan savaş yaşanmamışsa da bu iki ülke kozlarını başka ülkelerin iç savaşında paylaşmıştır. Öğrenciler beşinci sıradaysa uluslararası kuruluşların oluşmasını önemli görmüştür. Öğrencilerden bir kısmı bu kuruluşların görevlerini adaletli bir şekilde yerine getirmediğini söylemelerine rağmen dünya barışı için bu kuruluşları önemsediklerini göstermiştir. Öğrenciler altıncı sıradaysa Sovyetler Birliği'nin kurulması ve dağılması kategorisini tercih etmiştir. Bu kategoriyi en önemli gören öğrenciler Sovyetler Birliği'nin kurulmasının dünyayı ideolojik, politik ve siyasal olarak etkilediğini dile getirmiştir. Öğrenciler yedinci sıradaysa moda, müzik ve sporun küreselleşmesi adlı kategoriyi tercih etmiştir. Öğrenciler son sıradaysa 1929 Ekonomik krizi ve diğer krizlerin tarihsel açıdan en önemli olduğu kategorisini tercih etmiştir. Ekonomik krizler ve dalgalanmalar öğrenciler tarafından en az tarihsel öneme sahip olan kategori olmuştur. Levstik'in (2008) yılında yaptığ çalışmada 48 öğrenciden sadece bir kişi ekonomik kriz konusunu tarihsel öneme sahip olay olarak tercih etmiştir. Her iki çalışmada öğrencilerin ekonomik konularla ilgili olayları tarihsel önem bakımından çok gerilerde tercih ettiğini göstermektedir.

$\mathrm{Bu}$ çalı̧̧mada tarihsel olaylar dokuz kategori altında toplanarak öğrencilerden değerlendirilmeleri istenmiştir. Bundan sonra yapılacak olan çalışmalarda

Olaylar tek başlık halinde öğrencilere sunularak görüş alınabilir. Böylece benzer ya da farklı kategori oluşturan olayların önemine ilişkin öğrencilerin görüşleri net bir şekilde alınabilecektir. Savaşlar, bilimsel gelişmeler, ekonomik krizler gibi tarihsel konular kendi içerisinde önem açısından karşılaştırılabilir.

Öğrencilerin olaylara yükledikleri tarihsel olay çeşitli değişkenlere göre değerlendirilebilir. Öğrencilerin cinsiyeti, mensup oldukları bölge, sosyo- ekonomik düzey gibi konuların öğrencilerin algısında farklılık yaratıp yaratmadığ 1 araştırılabilir.

Öğrencilerin okudukları üniversiteler, okudukları bölümlerin tarihsel önem açısından farklılık yaratıp yaratmadığı da incelenebilir.

Bu çalışma dünya tarihindeki olayların önemine yönelik yapılmıştır. Bunun yanında ulusal tarihteki olayların önemine yönelik de öğrencilerle tarihsel önem konusunda çalışma yapılmasının alana katkı sağlayacağı düşünülmektedir. 


\section{Kaynakça}

Barton, K. C. (2005). "Best Not to Forget Them": Secondary Students' Judgements of Historical Significance in Northern Ireland. Theory and Reserach in Social Education, 33 (1), 9-44.

Barton K C and Levstik L. S (2008) It Wasn't a Good Part of History, National Idendity and Students' Explanations of Historical Significance. Researching in History Education, New York: Routledge, 240-272.

Hobsbawn, E. (1999). Tarih Üzerine, Çev. Osman Akınhay, Ankara: Bilim ve Sanat Yayınları.

James H.L ve Diğerleri (2009). Representing World History in the 21st Century: The Impact of 9/11, the Iraq War, and the Nation-State on Dynamics of Collective Remembering. Journal of Cross-Cultural Psychology, 40 (4). http ://jcc.sagepub.com at Victoria Univ of Wellington on July 11, 2009.

Karasar, N. (2005). Bilimsel Araştırma Yöntemi, 14. Baskı. Ankara: Nobel Yayınları.

Komisyon. (2012). Çağdaş Türk ve Dünya Tarihi Dersi Öğretim Programı. Ankara: Milli Eğitim Bakanlığı.

Okur Y. ve Diğerleri (2010). Çağdaş Türk ve Dünya Tarihi. Ankara: MEB Yayınları.

Levstik, L.S. (1997-1998). Early Adolescents' Understanding of the Historical Significance of Women Rights. International Journal Of Social Education, 12 (2), 19-26.

Levstik, L. (2008). Articulating the Silences, Teachers' and Adolescents' Conceptions of Historical Significance. Researching History Education, 273-292, New York and London: Routledge. Levstik, L. (2008). What Makes the Past Worth Knowing. Researching History Education, New York and London: Routledge, 228-240.

Levstik, L. and Barton K. C. (2008). Doing History, Third Edition, New York and London: Routledge.

Liu ve Diğerleri (2009). Representing World History in the 21st Century. Journal of Cross-Cultural Psycholgy , 40 (4), 667-692. Downlanded from http://jcc.sagepub.com at Victoria univ of Wellington on july $11,2009$.

Sexias, Peter (1994). Students' Understanding of Historical Significance. Theory and Research in Social Education, Vol. XXII (3), 281-304.

Terzian, S. G. (2007). That's When We Became a Nation, Urban Latino Adolsecents and the Designation of Historical Significance. Urban Education, 42 (1), 52-81.

Wallece M (2000). Integrating United States and World History in the High School Curriculum: The Trials and Tribulations of a Good Idea. The History Teacher, 33 (4), 483-494. http:// www.jstor.org.stable/494944 27/07/2010 21:59.

Yeager E. A., Foster J.F., Greer J (2002). How Eight Graders in England and the United States View Historical Significance. The Elementary School Journal, 103 (2), 199-219.

Yıldırım, A ve Şimşek, H. (2006). Nitel Araştırma Yöntemleri, Ankara: Seçkin Yayıncılık. 


\section{EK}

\section{Üniversite Öğrencilerinin Görüşlerine Göre Çağdaş Dünya Tarihi Konularının Tarihsel Önemi}

Değerli öğrenciler size verilen dünya tarihi ile ilgili başlıklardan (kategori) hangisinin insanlık tarihi açısından en önemli olduğunu düşünüyorsunuz? Sizlere verilen dokuz başlıkla (kategori) ilgili örnekler de sunulmuştur. Aşağıda verilen başlıklardan birisini seçip ilgili kutucuğa işaret ( $X$ ) koyarak seçiminize yönelik kısa bir açıklama yapabilir misiniz?

Kişisel Bilgiler

1. ( ) Erkek

2. ( ) Kadın

Sinıfınız:

\section{Konular}

\begin{tabular}{|c|c|}
\hline 1. ( ) & $\begin{array}{l}\text { Savaşlar (Birinci ve İkinci Dünya Savaşları, İspanya İç Savaşı, Afrika'da yaşanan iç savaşlar, } \\
\text { Arap-İsrail Savaşları, İran-Irak Savaşı, Körfez Savaşları, Arap Baharı ve çatışmalar, İran } \\
\text { Devrimi, Baas Hareketi) savaşlar sonucunda değişen sınırlar, imparatorlukların } \\
\text { dağılması ve yeni devletlerin kurulması, yeni rejimler, siyasi antlaşmalar, savaşın } \\
\text { insanlık için getirdiği yıkım, savaşlarda yeni silahların kullanılması....) }\end{array}$ \\
\hline 2.( ) & $\begin{array}{l}\text { Sovyetler Birliği'nin Kuruluşu ve Dağılması (Bolşevik Devrimi, Komünist anlayışa göre yeni } \\
\text { ekonomik yapılanma, Glasnost ve Perestroika, SSCB'nin ve Komünist yönetimlerin yı- } \\
\text { kılması, Türk Cumhuriyetleri'nin bağımsız olması, Azerbaycan-Ermenistan Savaşı, Yu- } \\
\text { goslavya'da iç savaş, ABD'nin ve AB'nin Doğu Avrupa'da Sovyetlerin yarattığıoşluğu } \\
\text { doldurmak istemesi, Sovyetlerin yıkılmasıyla ABD’nin rakipsiz kalması....) }\end{array}$ \\
\hline 3. ( ) & 1929 Ekonomik Krizi ve Diğer Ekonomik Kirizler... \\
\hline 4. ( ) & 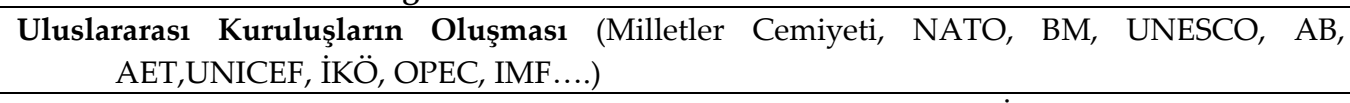 \\
\hline 5. ( ) & $\begin{array}{l}\text { Asya ve Afrika'da Yeni Devletler'in Kuruluşu (Hindistan, Pakistan, İsrail, Çin Halk Cumhu- } \\
\text { riyeti'nin kurulması, Afrika ve Asya'da Sömürgeciliğin kalkması nedeniyle kurulan yeni } \\
\text { devletler....) }\end{array}$ \\
\hline 6. ( ) & $\begin{array}{l}\text { Soğuk Savaş Dönemi Mücadele ve Savaşlar (ABD- Sovyet Rekabeti, Cominform'un kuruluşu, } \\
\text { SSCB'ye karşı Macar milli ayaklanması, Varşova Paktı Ordusu'nun Çekoslovakya'yı } \\
\text { işgali, Kore Savaşı, Vietnam Savaşı, Balkan Paktı'nın Kurulması, Bağdat Paktı'nı } \\
\text { Kurulması, Yunan İç Savaşı, Sovyetlerin Doğu Avrupa'da yayılması, Truman Doktrini, } \\
\text { Marshal Yardımı....) }\end{array}$ \\
\hline 7.( ) & $\begin{array}{l}\text { İcatlar ile Teknolojik ve Bilimsel Gelişmeler (TV, Telefon, İnternet ve Otomobilin } \\
\text { yaygınlaşması, DNA'nın Keşfi, Atomun Parçalanması, Lazerin icadı, Video kaset, Hafıza } \\
\text { kartı, Hepatit B aşısı, Doly adlı koyunun kopyalanması, Uluslararası uzay istasyonu ve } \\
\text { Mars'ta incelemeler....) }\end{array}$ \\
\hline $8 .($ ) & $\begin{array}{l}\text { Küresel Sorunlar (AIDS, Kuş Gribi, Kırım Kongo Ateşli hastalığı, kanserin yaygınlaşması, } \\
\text { depremler, küresel ısınma, çevresel kirlilik, nükleer kazalar, yetersiz beslenme ve açlık, } \\
\text { işsizlik, su kaynaklarının azalması, nüfus artışı, uluslararası terör....) }\end{array}$ \\
\hline 9. ( ) & $\begin{array}{l}\text { Moda, Müzik, Sinema ve Sporun Küreselleşmesi (Olimpiyatlar, dünya kupası, Avrupa Futbol } \\
\text { Şampiyonası,Dünya Basketbol Şampiyonası Hollywood, pop ve rock müziği, Eurovi- } \\
\text { sion, Nobel Edebiyat Ödülü, Cannes Film Festivali, Titanic, Harry Potter, Madonna....) }\end{array}$ \\
\hline
\end{tabular}




\section{Extended Abstract}

\section{Purpose}

The purpose of the current study was to determine the views of the students attending to the department of history over the historical importance modern world history topics. It was found in the literature that there is a lack of practical researches over historical importance in Turkey, while this issue has been encountered as a topic of research in foreign countries. In academic papers, there have been some works over the importance of historical events, it was found that there is no study into how students and teachers perceive the importance of historical events. Depending on this idea, it was aimed to find out the views of students studying at the department of history, Faculty of Science and Literature of Kafkas University over the historical importance of the issues of Modern World History. In addition, the course book of Modern Turkish and World History is the only book in this field. The data obtained will give us clues about how university students approach the issues in this book.

\section{Method}

In this part of the study, research model, numerical data with regard to the genders and classes of the students in the working group will take place.

\section{The Research Model}

The method of this research is a qualitative survey. The design of the research is a case study. Case studies could be carried out through both quantitative and qualitative approach. The course book of Modern Turkish and World History was examined and the units were determined. The issues given in the units were classified under some certain headings thematically. Two academic staffs who were experts of history education were consulted about these headings. As a result of the feedback taken from the experts, the historical events given in the history course book were gathered under nine categories. These categories were; Wars, the Establishment and Collapse of Soviet Union, 1929 World Economic Crisis and Other Crisis, Formation of International Institutions, the Creation of New States in Asia and Africa, Cold War Period Struggles and Wars, Inventions and Technological and Scientific Developments, Global Problems, Fashion, Music, Globalization of Cinema and Sport. These categories were offered to students as documents. They were asked which of these categories that were given to them were the most important in terms of world history and they were also asked to give the reason.

\section{Working Group}

This study was applied in Kafkas University, Faculty of Science and Literature, the Department of History. Out of the purposeful sampling methods, standard sampling method was used in the study. The basic sense in this sampling method is a case study standing for a series of standards that were determined beforehand. The reason why the department of history was preferred was that it was thought that the knowledge and awareness level of students of this department is high with regard the issues of world history. In addition, the students of history department are the candidates of history teachers. The course of Modern Turkish and World History taught in the secondary education will be taught by these teachers in the future. One hundred ninety-eight students were included in the study. While samples from student answers were given in the study, boy students were coded as (B) and girl students were coded as (G). Also, the knowledge of which class the students attended were added. 


\section{Findings and Discussion}

Rapid change in the world can also lead to a change in the interests and needs of humans. Human beings have to obtain new information in order to keep up with any change. These changes are reflected in the educational system and lead to changes in the program. The science of history is also affected by this change at a significant rate. The recent changes experienced in the history program are a clear proof of this case. With the addition of the course of Modern Turkish and World History to the program of the course of history in the secondary education, these events having a history of almost a century were included in the program. The course book includes an intensive knowledge of a hundred years, since $20^{\text {th }}$ century has witnessed both political, scientific and economic significant changes. Besides that, dealing with historical events in the Far East and in the continent of Africa is a significant development in terms of teaching world history. In that way, teaching world history will be free from being a European centered teaching. It is also an indication that Turkish historiography has new horizons. Depending on the findings of the research, it was found that $46.4 \%$ of the students attending to the department of history regarded that wars are the most important events, $11.6 \%$ thought it was global problems, $10.1 \%$ thought it was inventions and technological and scientific developments, $9.5 \%$ believed it was cold war period struggles and wars, $6.5 \%$ thought it was formation of international institutions, $4.5 \%$ thought it was the establishment and collapse of Soviet Union, $4.0 \%$ believed it was the creation of new States in Asia and Africa, $4.0 \%$ believed it was fashion, music, the globalization of cinema and sport, and $3.0 \%$ thougt it was 1929 World Economic Crisis and other crisis. The results of the research showed that the first choices of the university students and a great many candidates of history teachers were the issues of wars as the historically important ones. It is likely to say that the recommendations to reduce the wars issues in the history course books or putting them in the less important issues were not supported so much. Students put an importance on the issues of wars historically the most. Sexias (1994) found that students preferred wars as the events with a historically importance in the first place out of twenty-nine historical events. Yeager, Foster and Greer (2002) found in a study that American and British students preferred world wars as the most important events having a historical importance. These three studies revealed that student put an importance on the war issues to learn. University students thought that global issues are of historical importance in the second place. Students expressed that global issues are regarded as a threat on human life. In the third place, students chose the category of technological and scientific developments. Yeager, Foster and Greer (2002) found that US students preferred stepping on the Moon as the most important historical event in the third place. Depending on these two studies, it was found that even though student did not indicate scientific and technological developments as the most important historical events, they put it in the first three events.

In the fourth place, students named cold war period struggles and wars category. In the period of cold war, USA and USSR competed in the arena of civil wars of other countries even though they did not have a direct war with each other. Students indicated the formation of international institutions in the fifth place as a historically important event. Some of the students believed that these institutions are of importance even though they do not act fairly. In the sixth place, students preferred the establishment and collapse of Soviet Union. Those regarding this category as the most important one pointed out that the establishment of Soviet Union had an ideological and political impact on the world. Students named fashion and globalization of music and sport in the seventh place. In the last place, students preferred 1929 economic crisis and other crises in terms of the most important historical events. Economic crisis and fluctuations were regarded as the least important historical events by the students. Levstik (2008) 
pointed out in a study that only one student out of 48 preferred economic crisis as the historically important events. In both studies it was found that students preferred the issue of economic crisis in the last place in terms of historical importance.

\section{Conclusion}

In the current study, historical events were classified in nine categories and students were asked to grade them. In the future studies, these events could be given to students under just one heading and students could be asked to give their opinions. In that way, the views of the students with regard to the importance of the events comprising similar or different categories could be easily asked. Such historical events as wars, scientific developments and economic crisis could be compared in terms of their importance. The historical mission given on the events by the students could be evaluated in terms of different variables. Whether such issues as the genders of students, the region they belong to, and their socioeconomic levels differed in the perception of them could also be investigated. Whether the universities and the departments students attend differed in terms of historical importance could also be investigated. This study was carried out aiming at the importance of events in the history of the world. Besides that, it is believed that studies to be carried out over historical importance with the students in terms of the importance of events in national history would make a contribution to the issue. 